\title{
The early development of the steam engine: an evolutionary interpretation using complexity theory
}

\author{
Koen Frenken and Alessandro Nuvolari
}

In this paper we analyse the early development of the steam engine as a search process in a multidimensional design space. This perspective allows us to make use of recent insights coming from complex systems theory, in particular, of a generalized version of Kauffman's NK-model. We analyse yearly distributions of steam engine designs and their sectors of application for the period 1760-1800. We interpret the patterns of variety and differentiation characterizing the behaviour of these distributions as emerging properties of underlying search processes unfolding in the design space. We conclude that the early development of steam power technology can be understood as a process of 'technological speciation' of various engine designs in distinct users' niches.

\section{Introduction}

Traditional accounts of the evolution of the steam engine, such as Thurston (1939) or Dickinson (1938), have described the early development of this technology as a 'linear' succession of technological breakthroughs. In these works, the process of technical change is essentially conceived as a sequence of rather dramatic 'acts of invention' with individual inventors such as Savery, Newcomen, Watt and Trevithick successfully tackling the shortcomings of the existing 'state of the art' by contriving technical improvements that made extant designs obsolete. In this view, technological evolution seems to have been characterized by an almost inescapable logic of progression.

The study of the specific technical merits of individual inventions vis-à-vis the existing state of the art is an inevitable component of any account of the long-term evolution of a technology. However, as emphasized by Rosenberg (1976), this perspective, although capable of illuminating some critical facets of technological development, provides us with an incomplete appreciation of the overall process of technological change. A deeper understanding calls for a broader narrative frame in which attention is not only devoted to the original acts of invention, but also to the phases of adoption and diffusion of the technology. ${ }^{1}$

\footnotetext{
${ }^{1}$ Notably, Rosenberg (1976: 189-191) mentions the work of Dickinson (1938) as a typical example of an account of technical change, which pays scant attention to diffusion.
} 
In this article we offer an interpretation of the early history of the steam engine that tries to integrate patterns of invention and diffusion in a unified account. In order to do so, we represent the development of steam power technology as a search process in a multidimensional design space. This perspective allows us to make use of recent insights emerging from complex systems theory. In particular, we will make use of a generalized version of Kauffman's NK-model that regards technological evolution as a trial-and-error search process on a fitness landscape. The generalized version of the NK-model allows us to consider the role played by distinct selection environments, reflecting the different contexts of application of particular designs. We also set out a framework based on entropy statistics, which is susceptible of a relatively straightforward interpretation in terms of the NK-model. In this way, we are able to provide a systematic description of the patterns of variety and speciation characterizing the early history of the steam engine.

Our empirical results will show that technological evolution in early steam engines was characterized by growing variety and differentiation into distinct design species. Our interpretation of this pattern points to the crucial influence exerted by different application domains on the evolution of the technology. Early steam engine designs were endowed with different trade-offs among the relevant performance attributes, so that each of them resulted more or less 'fit' into a specific 'ecological' niche. In other words, application domains represented distinctive selection environments. These distinct selection environments prompted the emergence of differentiated design trajectories. As we will show, this process is akin to 'speciation' in biology. The remaining of the article is structured as follows. In the next section, we provide a brief outline of the early history of steam power technology. Section 3 introduces the generalized NK-model proposed by Altenberg $(1994,1995)$. In Section 4 we reconstruct the design space of early steam engine technology and present the dataset that is used throughout the study. Entropy statistics are introduced in Section 5. In Section 6 we present our empirical results and in Section 7 we discuss them on the background of previous historical studies. Section 8 draws conclusions.

\section{The early development of the steam engine}

In this section we summarize the main contours of what might be called the traditional account of the early development of the steam engine. This section will also provide the indispensable background (in the history of technology) relevant to our study.

Most historical accounts of the development of the steam engine agree in placing the 'date of birth' of this technology in the last decade of the seventeenth century with the machine invented by Thomas Savery. In the late seventeenth century mining activities in Britain began to be severely hampered by flooding problems. Following the scientific investigations of Torricelli and Pascal, there were several attempts to use atmospheric pressure to lift water out of mines. ${ }^{2}$ The Savery engine, clearly inspired by the scientific

${ }^{2}$ On the powerful influence exerted by mining concerns in Britain on seventeenth century scientific and technological developments, see Merton (1938: ch. 7). 
investigations of the time, can be considered as the first successful effort in this direction. The engine was developed in the period 1695-1702. In the Savery engine, steam was first admitted and then condensed inside a 'receiving' vessel by pouring cold water over its exterior surface. Once the steam had condensed, atmospheric pressure drove the water to be pumped up into the vessel. The engine suffered two major shortcomings, which severely limited its practical utilization. The first defect was the restricted height of operation: the suction lift could raise water only to a height of $20 \mathrm{ft}$ (about $6 \mathrm{~m}$ ). The second drawback was the high fuel consumption due to the need to recreate steam inside the vessel at each stroke. Undoubtedly, the historical importance of the Savery engine lies more in its showing the general potentialities of the use of steam power rather than in its practical applications.

The Newcomen engine, developed in 1712, resolved the problem of the limited height of operation. The engine consisted of a piston-cylinder arrangement connected to one hand of a rocking beam. The opposite end of the beam was connected to the mine pump rod. Steam was admitted from the boiler into the cylinder by means of a valve. Then a cold jet of water was sprayed into the cylinder, condensing the steam. This created a partial vacuum inside of the cylinder, so that the piston was pushed down by atmospheric pressure ${ }^{3}$ (the top of the cylinder was open), lifting the pump rod at the other end of the beam. The use of the cylinder-piston arrangement in combination with the beam made it possible to use the engine for an effective mine drainage, as pump rods could easily be extended to reach the necessary depth. Furthermore, the Newcomen engine was robust, highly reliable and based on a fairly simple working principle. Given these merits, it is not surprising that Newcomen engines soon became widely used in mining activities. However, the Newcomen engine had two main technical shortcomings. As with the Savery engine, one deficiency was the high fuel consumption due to the need to cool and heat the cylinder at each stroke. The second limitation was the irregularity of its movement, which prevented the use of this kind of engine for directly delivering rotary motion. ${ }^{4}$

James Watt tackled the problem of the high fuel consumption of the Newcomen engine in the late 1760s and early 1770s. In his engine (patented in 1769) condensation was carried out in a separate vessel and not in the cylinder, so there was no need to reheat the cylinder at each stroke. The Watt engine, like the Newcomen engine, consists of a piston-cylinder arrangement connected with a rocking beam, but the piston is pushed down by the action of steam and not by atmospheric pressure (the cylinder has a closed top). After having pushed down the piston, the steam is admitted by means of a system of valves into a separate vessel where it is condensed. This allows for a much higher fuel economy compared to the Newcomen engine.

\footnotetext{
${ }^{3}$ For this reason Newcomen engines were also known as 'atmospheric engines'.

${ }^{4}$ Newcomen engines were successfully used to raise water over a water wheel, which, in turn, delivered rotary motion suitable for powering machinery. This type of engine was called 'water returning. One major limitation of this arrangement was that the inefficiency of the water wheel was combined with the inefficiency of the engine (Hills, 1989: 49).
} 
In the second half of the eighteenth century, attempts were made to modify the Newcomen engine so that it could deliver a steady rotary motion. James Pickard patented the most convenient solution involving the combined use of the crank and a flywheel in 1780 (Hills, 1989: 60). Pushed by the insistence of his business partner Matthew Boulton, Watt, at the time, was also working at the transformation of reciprocating into rotary motion. Pre-empted by Pickard in the use of the crank, Watt was forced to create an alternative mechanical device, the 'sun and planet' gear. However, after the expiration of Pickard's patent in 1794, Boulton and Watt resorted to the use of the more effective crank (von Tunzelmann, 1978: 20). The conversion of reciprocating into rotary motion was also facilitated by the development of the double-acting engine, another invention of Watt, which was patented in 1782. In the double-acting engine steam is alternatively admitted into the cylinder on both sides of the piston. This resulted in a more powerful action, but also in a much more uniform movement of the piston, rendering the Boulton and Watt double-acting design stateof-the-art for many rotary applications. Finally, in the second half of the 1790s, Richard Trevithick developed the first high-pressure engine (Watt engines used steam at a little more than atmospheric pressure). This type of engines did not use the separate condenser, but discharged exhaust steam directly into the atmosphere. For this reason, they were called 'puffers'. The main advantage of this type of engine was its compactness and cheaper cost of installation due to elimination of the condenser, the air pump and the beam (von Tunzelmann, 1978: 23).

Clearly, this account focuses on the inventive activities of individual inventors (the line Savery-Newcomen-Watt-Trevithick). ${ }^{5}$ Indeed, in the most extreme versions (Thurston, 1939), such historical depiction is akin to chronicling a sort of 'glorious march of invention'. Implicit in this clean-line narrative is the notion that the evolution of a technology consists in a process of successive technological 'substitutions' where novel (better performing) technologies replace the established ones (Fisher and Pry, 1971).

Economic historians have paid more attention to the diffusion of the various types of steam engines into different sectors than to original acts of inventions. From these studies a somewhat more complex picture emerges, as the rates of adoption and the domains of application of the various engines are the variables to be explained. Hills (1970) and von Tunzelmann (1978), for example, aptly pointed out that Newcomen and Watt engines co-existed for a very long period. ${ }^{6}$ Newcomen engines were generally favoured on the grounds of their cost advantage in purchase, whereas Watt engines were

\footnotetext{
${ }^{5}$ The contributions of Donald Cardwell $(1963,1971,1994)$ are also rather exclusively focused on the activities of individual inventors. However, it is worth remarking that Cardwell's aim was to shed light on the nature of the relation between scientific advances and technical change in this historical period, rather than on the evolution of steam power technology per se. This led him to consider in detail the scientific background underlying single acts of invention.

${ }^{6}$ On the longevity (in some remarkable cases well into the twentieth century) of Newcomen engines, see Rolt and Allen (1977: 130).
} 
superior in fuel efficiency. Thus, in areas where coal was cheap, Newcomen engines had an important advantage over Watt.

In our interpretation, in the case of early steam engine development, the economist's type of consideration cannot be accommodated into the traditional linear picture by merely assuming a slow diffusion of 'best-practice' technology (so that two technologies only co-exist in the transition phase). Rather, a careful reading of the contributions of Hills and von Tunzelmann suggests that technological development is better characterized by the formation of two 'design families' or 'design species', each of them tailored to a different set of users' needs. The aim of the rest of the paper is to reconsider the pattern of diffusion of various types of steam engines in distinct application sectors. We will suggest that the overall pattern of diffusion can be best interpreted as the outcome of a complex evolutionary process of search and selection unfolding on a fitness landscape, characterized by a number of distinct technological niches, rather than as a linear and unidirectional sequence of technological substitution processes. Importantly, our results point to a pattern of evolution that is even more complex than the emergence of two design species as described by Hills (1970) and von Tunzelmann (1978).

\section{A model of technological evolution on complex fitness landscapes}

The view of technological evolution as a sequence of successive technological substitutions regards competition between designs in terms of simple and clear-cut cost comparisons. This perspective does not take into account that technologies are complex systems both with regard to their internal structure and their usage possibilities. Technologies embody a large set of design dimensions that interact in complex ways (Simon, 1969) and are subject to heterogeneous demand regarding the desired levels of performance attributes (Lancaster, 1979). Here we propose an alternative view that can account for more complex patterns of technological evolution including speciation of designs into differentiated niches of heterogeneous users. In particular, we suggest an interpretive framework for the study of technological evolution, which is based on Altenberg's $(1994,1995)$ generalization of Kauffman's (1993) NK-model ${ }^{7}$ of fitness landscapes.

Our starting point is the notion of design space of a technology (Bradshaw, 1992), which allows us to describe technological change as a search process on a fitness landscape. A design space specifies the principal technical dimensions, or constituting elements, of a technology, so that each design can be represented by a point in a multi-dimensional space. Let $N$ denote the number of principal dimensions of the

\footnotetext{
${ }^{7}$ Kauffman's (1993) NK model has recently inspired a number of evolutionary simulations models in economics and organization theory (Kauffman and Macready, 1995; Levinthal, 1997; Frenken et al., 1999a; Gavetti and Levinthal, 2000; Marengo et al., 2000; Rivkin, 2000; Frenken, 2001; Simon, 2002; Dosi et al., 2003).
} 
technology in question. Each dimension $i(i=1, \ldots, N)$ can assume $A_{i}$ possible states, which, maintaining the biological term, we will call 'alleles', coded as '0', '1', '2', etc. For example, in the steam engine case, we can distinguish, among others, the dimension 'steam pressure' $(0=$ low; $1=$ high $)$ and the dimension 'condenser' ( $0=$ present; $1=$ absent). In this way, each possible design $s$ can be described by a string $s_{1} s_{2} \ldots s_{N}$, such that:

$$
s \in S ; \quad s=s_{1} s_{2} \ldots s_{N} ; \quad s_{i} \in\left\{0,1, \ldots, A_{i}-1\right\}
$$

Correspondingly, the overall size of the design space of all possible combinations between alleles, is given by the product of the number of alleles per dimension:

$$
S=\prod_{i=1}^{N} A_{i}
$$

Given that technological artefacts will be typically constituted by many dimensions and by many alleles for each dimension, searching for the optimal design by simply testing all possible combinations between alleles would generally be a too costly strategy, due to the high number of possibilities. Rather, the design task amounts to applying a search strategy that permits to find a string with reasonable performance (fitness) in a relatively short time. Designers will typically follow satisficing rather than optimizing strategies (Simon, 1969; Frenken et al., 1999a).

\subsection{Altenberg's generalized NK approach}

The (heuristic) search process in the design space can be represented as a search on a fitness landscape. As we shall see, this perspective is very close to the model of blindvariation and selective retention set out by Walter Vincenti in his studies of engineering design activities in the aircraft industry (Vincenti, 1990: ch. 8; Vincenti, 1994).

Here, we will adopt a more recent generalized version of Kauffman's NK-model proposed by Altenberg $(1994,1995)$. In Altenberg's model, the fitness landscape is constructed by assigning individual fitness values to an $F$ number of functions $(f=1, \ldots, F)$ for each possible point $s$ of the design space. In this respect, one can note the analogy with genetic strings that are also composed by a set of alleles describing the genotype of the organism, and by a list of traits (phenotype), which are subject to the selection pressure of the environment. The difference between Altenberg's and Kauffman's models is that in the former the number of dimensions $N$ is not necessarily equal to the number of functions $F$, while in the latter approach it is assumed that $N$ is equal to F. Hence, Altenberg's model is a generalization of Kauffman's model because it can represent a complex system with any number of design dimensions and with any number of functions.

The first step in applying the model to the study of technological evolution is to

\footnotetext{
${ }^{8}$ Note that, since the first allele is labelled as ' 0 ', for each dimension the possible alleles range from 0 to $A_{i}-1$.
} 


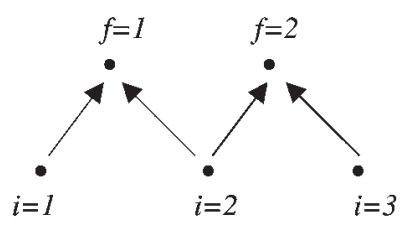

Figure 1 Example of a genotype-phenotype map $(N=3, F=2)$.

identify the $N$ constituting elements, or design dimensions, of the technology in question and the $F$ functions it performs. In our steam engine case, design dimensions include, among others, one or two cylinders, open or closed top, and condensing or not condensing. Functions of steam engine include fuel efficiency, maintenance cost, power, safety, etc. In this way, the internal structure or 'architecture' of a complex system can be represented by means of a 'genotype-phenotype map'. In case of technologies, the map (or matrix) indicates which design dimension affects which function. Figure 1 gives an example of a map for a system with three design dimensions $(N=3)$ performing two functions $(F=2)$. Note that the mapping of the $N$ design dimensions (describing the internal structure of the technology) to the $F$ selection criteria (describing the services that the technology performs for its users) is a way to represent the 'imaging' of technical characteristics onto service characteristics posited by Saviotti and Metcalfe (1984).

The pleiotropy of a design dimension is defined as the number of functions that are affected by changes of its allele. Correspondingly, the polygeny of a function is defined as the number of design dimensions whose changes have an effect on its fitness. ${ }^{9}$ In the example of Figure 1, the polygeny of both functions is equal to two, while the pleiotropy of design dimensions $i=1$ and $i=3$ is equal to one and the pleiotropy of design dimension $i=2$ is equal to two. Accordingly, any complex system can be described by $N$, $F$ and the matrix specifying the relationships between design dimensions and functions. Polygeny of functions implies that in order to maximize the value of one function it is necessary to properly tune all the dimensions that have an effect on it. However, since design dimensions are generally pleiotropic (i.e. they typically affect more than one function), maximizing one function by tuning several dimensions will generally imply a loss of performance in other functions.

To construct the fitness landscape corresponding to a particular dimension-function map, it is necessary to assign a new fitness value $w_{f}$ for each function $f$ of the system, when a mutation occurs in one of the dimensions that affect function $f$. In other words, each time a dimension is mutated by changing its allele, all the functions that are affected by the change according to the genotype-phenotype map are assigned a new randomly drawn fitness value $w_{f}$. Following Kauffman and Altenberg, we extract the fitness values for each function from the uniform probability distribution on the

${ }^{9}$ Kauffman's (1993) original NK model can now be interpreted as a special case of Altenberg (1994, 1995) model with $F=N$ and polygeny equal to $K+1$ for all the $N$ dimensions. 


$\begin{array}{cccc}\text { String } & \mathbf{w}_{\mathbf{1}} & \mathbf{w}_{\mathbf{2}} & \mathbf{W} \\ 000: & 0.8 & 0.9 & 0.85 \\ 001: & 0.8 & 0.6 & 0.70 \\ 010: & 0.4 & 0.3 & 0.35 \\ 011: & 0.4 & 0.2 & 0.30 \\ 100: & 0.2 & 0.9 & 0.55 \\ 101: & 0.2 & 0.6 & 0.40 \\ 110: & 0.9 & 0.3 & 0.60 \\ 111: & 0.9 & 0.2 & 0.55\end{array}$

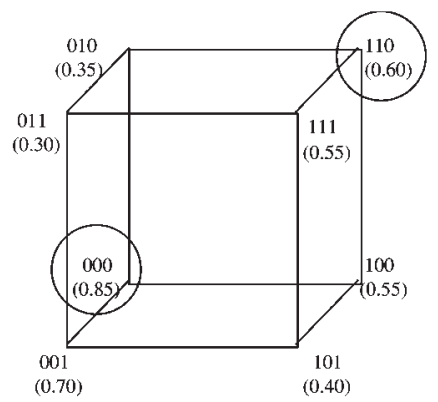

Figure 2 Simulation of the fitness landscape for the genotype-phenotype map of Figure 1.

interval $[0,1]$. The total fitness $W$ of a design string $s$ can be expressed as the mean of the fitness values of all the $F$ functions:

$$
W(s)=\frac{1}{F} \cdot \sum_{f=1}^{F} w_{f}
$$

A simulation of the fitness landscape example of the genotype-phenotype map of Figure 1 is given in Figure 2 for all the eight combinations in the design space. Local optima are circled reflecting the strings of alleles that are complementary: any mutation in one dimension would lead to a decrease in total fitness. Hill-climbing, i.e. improving the fitness of a design by mutating one dimension at the time and accepting the new string when fitness increases, always leads a designer to a local optimum. The precise local optimum that is found depends on the starting string and the sequence of mutations that followed thereafter. The existence of local optima reflects trade-offs between functions: in our example, increasing the fitness of one function can only be achieved by lowering the fitness of the other one and vice versa. Design 000 is optimal with regard to the first function and design 110 with regard to the second function, while there exists no design that is optimal in terms of both functions. The number of local optima on a fitness landscape (or its 'ruggedness') rises for increasing polygeny (complexity of the artefact) and increasing $N$ (dimensionality of its design space) (Kauffman, 1993; Altenberg, 1994). ${ }^{10}$

\subsection{Alternative fitness functions}

It is possible to introduce a second generalization in Kauffman's original NK-model by adopting more general fitness functions. The fitness function in equation (3) specified

\footnotetext{
${ }^{10}$ If polygeny is equal to one for all functions, only one global optimum exists in the fitness landscape, which is always found by hill-climbing. In this case, all functions are only affected by one dimension, so that the state of each dimension will never interfere with the state of another element. Further note that a polygeny value of one for all functions corresponds to $K=0$ in Kauffman's original NK-model (given $F=N)$.
} 
that total fitness is equal to the mean of fitness components (i.e. each function is equally weighted by users). Although this formulation may be convenient in simulation models, the equation obviously does not account for the (more general) case in which users apply different weights to different functions (as is assumed in hedonic price regressions). In fact, users will generally rank the various functions differently giving more importance to some performance attributes than to others. A simple specification capturing the different ranking of functions is given by:

$$
\begin{aligned}
& W(s)=\sum_{f=1}^{F} \beta_{f} \cdot w_{f}(s) \\
& \sum_{f=1}^{F} \beta_{f}=1, \quad \beta_{f}>0
\end{aligned}
$$

The concept of a fitness landscape does not change when total fitness is computed as a weighted sum instead of the simple mean of fitness values. However, the values of total fitness of each design $W(s)$ will be different depending on the values of the weights that are applied.

\subsection{User heterogeneity}

Another rather straightforward generalization of the NK-model is to allow for demand heterogeneity among users (Frenken, 2001). So far, we implicitly assumed that each user of a particular design applies the same set of weights $\beta_{\mathrm{f}}$ and thus assigns the same fitness value $W$ to a design $s$. However, depending on the use of a design in a particular context, users can evaluate differently the functional attributes of the technology and apply different weights to them (Lancaster, 1979). In this way, different user groups can assign different values of total fitness to one and the same design.

Formally, the weights assigned to functions as specified above $\left\{\beta_{1}, \beta_{2}, \ldots, \beta_{\mathrm{f}}\right\}$ reflect one homogeneous user group. When there exists more than one user group, we can characterize each user group by a different set of weights. Accordingly, for a number $G$ of user groups $(g=1, \ldots, G)$, the fitness of a particular design for user group $g\left(W_{g}\right)$ is given by:

$$
W_{g}(s)=\sum_{f=1}^{F} \beta_{f g} \cdot w_{f}(s)
$$

\footnotetext{
${ }^{11}$ This is a relatively simple function sometimes applied in multi-criteria analysis of project selection (Nijkamp et al., 1990). One can envisage other functional forms, including a Cobb-Douglas type of fitness function $W(s)=\prod_{f=1}^{F} w_{f}(s)^{\beta f}$. The choice of the specific functional form, of course, will depend on the features of the selection processes that the model is supposed to represent.
} 


$$
\sum_{f=1}^{F} \beta_{f g}=1, \quad \beta_{f g} \geq 0
$$

When preferences are more dispersed, it is less likely that one design will be optimal for all user groups, and one may expect product differentiation to emerge in the multi-dimensional Hotelling-like space (Hotelling, 1929; Lancaster, 1979) spanned by the $F$ functions. In the extreme case, given a sufficiently large design space, a different design may be found for each different user group. Furthermore, when user groups exist for which the available designs do not provide extremely satisfactory solutions, search for designs can be prompted in new directions in order to find configurations of alleles better suited to their demands ('induced innovation'). Also note that when users are heterogeneous, the concept of local optima changes: strings are no longer necessarily locally optimal for all users, but locally optimal for one or more user groups.

\subsection{Implications}

A number of implications follow from the generalized NK-model: ${ }^{12}$

1. When demand is homogeneous $(G=1)$ and complexity is absent (i.e. polygeny is equal to one for all functions and pleiotropy is equal to one for all elements), there exists only one global optimum.

2. When demand is heterogeneous $(G>1)$ and complexity is absent, there exists only one global optimum, which is the same string for all the user groups. In this case, since there is no interdependency among design dimensions, each function can be optimized independently from the others. The global optimum is the point of the design space with the highest fitness level for each function and, for this reason, it is preferred by all user groups (note that this result does not hold when some functions are valued negatively by some user groups-a case that is not contemplated in formula $5 b)$.

3. When demand is homogeneous and complexity is present (i.e. polygeny is greater than one for at least one function), the fitness landscape might contain local optima. The expected number of local optima is a function of polygeny. Thus, technological differentiation can occur when different designers come up with different, locally optimal solutions that have similar total fitness values. Differentiation means here that multiple designs are more or less equally capable of meeting the functional requirements of a specific user group.

4. When demand is heterogeneous and complexity is present, both differentiation and speciation can occur. Differentiation among designs may occur within a user group because of the possibility of local optima as in (3). Speciation, meaning the 'specialization' of different designs into different areas of application (constituting distinct selection environments), can occur as heterogeneity in preferences may render different designs globally or locally optimal for different user groups.

\footnotetext{
${ }^{12}$ For a more detailed discussion, see Frenken (2001) and Frenken and Nuvolari (2004).
} 
In this perspective, the processes of innovation and technological substitution can be related to the degrees of complexity and demand heterogeneity of the technology in question. When complexity is absent (or very low), the introduction of an innovation (modelled as the introduction of a new string) will trigger a process of technological substitution provided that the new design will have higher overall fitness. Instead, when complexity is high, due to the existence of interdependencies, the new design may have higher fitness values for some functions and lower fitness values for others (with a similar value for total fitness). In this case the two designs represent local optima, and, in so far as they are both capable of attracting some portion of users' demand, the degree of variety of the product population will increase.

Analogously, homogeneity of users groups implies that all users will evaluate a new design in the same way [i.e. either positive (accept) or negative (reject)]. On the other hand, in case of demand heterogeneity (assuming the existence of some degree of interdependency among design dimensions) a novel design may well be considered as an improvement by some user groups, while being considered a worsening by others, leading to an increase of the variety of designs in the product population.

Note that in the case of heterogeneous user groups, design variety is expected to be more persistent than in the case of homogeneity of preferences. In the case of homogeneity, variety may slowly disappear as different locally optimal designs lose ground to the one design with highest fitness. In case of heterogeneity, instead, the speciation of one design into two distinct designs (each suited to the requirements of one specific user group) is self-enhancing: further development of each design is localised and subject to the pressures of the specific selection environment in which it is successful.

\section{The construction of the design space of steam engine technology}

In our interpretation, the design space for early steam power technology can be conceived as constituted by seven basic dimensions. For each dimension, we can distinguish two possible alleles, except for one dimension for which we can individuate three possible alleles. Hence, the size of the design space is equal to $2^{6} \times 3=192$ possible steam engine designs. Throughout the following, we label each dimension as $X_{i}(i=$ $1, \ldots, 7)$. The design dimensions and alleles are given in Table $1 .^{13}$

Making use of this conceptualization of the design space, we can represent each steam engine design as a unique string of alleles. In Table 2, we list 13 types of steam

\footnotetext{
${ }^{13}$ The dimensions we identified represent the major first-order components of the steam engine layout. As Vincenti has pointed out, most complex artefacts are constituted by a nested hierarchy of components and sub-components (Vincenti, 1990: 9). In this perspective, processes of variation and selective retention occur at all levels of the design hierarchy. Hence, the emergence of new design is usually followed by incremental improvements of performance as the alleles at the sub-component level are progressively fine-tuned. Our analysis considers only the combinatorial design problem at the highest level of design hierarchy.
} 
Table 1 Description of the design space

\begin{tabular}{llll}
\hline Element & Allele 0 & Allele 1 & Allele 2 \\
\hline$x_{1}$ & Low pressure & High pressure & \\
$x_{2}$ & Without separate condenser & With separate condenser & \\
$x_{3}$ & Single acting & Double acting & \\
$x_{4}$ & Not compounding & Compounding & Water returning \\
$x_{5}$ & Reciprocating & Rotary & \\
$X_{6}$ & Open top & Closed top & \\
$x_{7}$ & Single cylinder & Double cylinder & \\
\hline
\end{tabular}

Table 2 Description of different types of steam engines as strings of alleles

\begin{tabular}{|c|c|c|c|}
\hline String & Engine type & Date & Main producer/developer \\
\hline$(0000000)$ & Newcomen atmospheric engine ${ }^{a}$ & 1710 & Newcomen \& Calley (1712) \\
\hline$(0000200)$ & Newcomen water returning ${ }^{a}$ & 1731 & Oxley (1762) \\
\hline (0000100) & Newcomen rotary ${ }^{a}$ & 1762 & J. Pickard (1780) \\
\hline (0100010) & Watt engine ${ }^{a}$ & 1769 & Watt (1769) \\
\hline$(0100210)$ & Watt water returning ${ }^{a}$ & 1774 & Boulton \& Watt (1774) \\
\hline (0100110) & Watt rotary & & Boulton \& Watt (1782) \\
\hline (0101011) & Hornblower compound ${ }^{a}$ & 1779 & Hornblower (1781) \\
\hline$(0110110)$ & Watt rotary double acting engine ${ }^{a}$ & 1780 & Boulton \& Watt (1785) \\
\hline$(0100000)$ & Symington ${ }^{a}$ & 1787 & Symington (1792) \\
\hline (0000101) & Newcomen two cylinders engine ${ }^{a}$ & 1788 & $\begin{array}{l}\text { Bateman \& Sherratt (1794); } \\
\text { Thompson (1793) }\end{array}$ \\
\hline$(1010110)$ & Trevithick's 'Puffer'a & 1799 & Trevithick (1802) \\
\hline$(1100010)$ & Trevithick 'Cornish' engine & & Trevithick (1812) \\
\hline (1101011) & Woolf 'Cornish' engine & & Woolf (1814) \\
\hline
\end{tabular}

aDesigns that occur in Kanefsky's dataset. For these designs, the dates in the third column refer to first appearance in the dataset. These may differ from the date used traditionally by historians of technology (e.g. 1712 for the first Newcomen engine). The last column is taken from Farey (1827) and indicates the main producer/developer of the engine design. The date corresponds to the erection of some particular noteworthy engine of that particular design.

engines characterizing the development of steam power technology up to 1812. Note that these 13 designs constitute only a small subset of all 192 possible designs (about $7 \%)$. This already illustrates the non-random selective nature of search activity, as the 
large majority of designs that are technically conceivable were never introduced on the market.

It is worth noting that we do not consider the Savery-type engine. ${ }^{14}$ In fact, our conceptualization of the design space takes into account only engines based on the cylinder-piston arrangement. Some historians have actually argued that (not having moving parts) Savery engines ought to be more properly considered as steam pumps rather than as actual steam engines. Following Usher (1954: 347), we consider the Newcomen engine to have set out, as the first steam engine design, the dimensions of the design space, in which further technological developments have taken place.

Kanefsky and Robey (1980) compiled a survey of all the steam engines erected in Great Britain in the course of the eighteenth century. ${ }^{15}$ For each (known) steam engine erected in Britain during the period 1700-1800, they recorded the year of construction, the type (or design) of the engine (i.e. Newcomen, Watt, etc.), and the sector of application. These data are probably affected by some biases in both upward and downward directions. The principle source of overestimation is the double counting of engines that were moved from one place to another, whereas underestimation is mainly due to small engines that have left no trace in the records. Notwithstanding these limitations (which may result in some minor revisions in the future), the survey constitutes the most accurate attempt to trace the quantitative growth of steam power in Britain over the eighteenth century. In this article, we employ an up-to-date version of this dataset compiled by Kanefsky. ${ }^{16}$

We limit ourselves to the period 1760-1800. The choice of the period has been motivated by the fact that before 1760 only Newcomen reciprocating engines (0000000) and Savery engines are present in the dataset. Since we do not take into account Savery engines in our analysis, as we consider these to be a pump technology, the product population in the period before 1760 consists exclusively of Newcomen engines. This initial period can thus be omitted from our analysis as differentiation and speciation are absent by definition.

In the database, we have 1369 engines (of known type) for the period 1760-1800. Each of these engines has been coded as a string of alleles, as illustrated in Tables 1 and 2. Unfortunately, we were not able to distinguish in our data between the Watt singleacting rotary engine (0100110) and the Watt double-acting rotary engine (0110110). We have decided to consider all the Watt rotary engines as double acting. Only few single-acting rotary engines are known to have been erected by Boulton and Watt. In addition, from 1787, the double acting became the typical standard proposed by the two partners for rotary applications (Farey, 1827: 444; Dickinson and Jenkins, 1927: 139-172).

\footnotetext{
${ }^{14}$ In our data-set only 33 Savery engines are present. Omitting these does not affect our results.

${ }^{15}$ See Kanefsky (1979) for a detailed account of the construction of the database.

${ }^{16}$ The list originally compiled by Kanefsky and Robey (1980) contained 2191 steam engines, the new updated dataset contains 2279 engines.
} 
Using the information on the sector of application of each engine provided by the database, we also classified each engine in one out of nine application sectors $(m \in M)$, namely:

1. coal mining

2. other mining (comprehending lead, copper, tin, iron and other mines)

3. cotton

4. other textiles (comprehending wool and other textiles)

5. metal working (comprehending ironworks, brass works, tinplate works, lead works and copper works)

6. food (comprehending distilleries, breweries, oil-mustard mills, flour mills, chocolate factories)

7. waterworks and canals

8. others

9. unknown

Our classification of sectors tries to capture the distinctive sets of functional requirements (representing different selection environments) of the various application sectors. Accordingly, we have distinguished between coal mining and other mining. The mining industry employed steam engines mainly for pumping water for mine drainage. Coal mining, however, can be considered a specific selection environment as in coal mines, engines could be very cheaply fed with 'slack' coal of inferior quality, which was otherwise not sellable. In the case of manufacturing applications, there were some sectors, as the food industries (in particular breweries, see Mathias, 1959) in which machinery could be easily powered by steam, while textile industries imposed tough requirements on the smoothness and steadiness of the motion that the engine was supposed to deliver. Within textiles, cotton fibres could be more easily subject to mechanized processes. ${ }^{17}$ This explains our choice of distinguishing between cotton and other textiles. The category 'others' consists of a number of niche applications including paper mills, sawmills and potteries. The 'unknown' category consists of 39 engines for which no data were available. ${ }^{18}$

\section{Entropy statistics}

The erection of a steam engine of a given design in a given year constitutes an observation in our seven-dimensional design space. In each year the product population is represented by the aggregation of all the engines constructed in that period (Saviotti, 1996). A straightforward way to analyse the evolution of multi-dimensional frequency

\footnotetext{
${ }^{17}[\mathrm{C}]$ otton proved to be the most tractable fibre technically. One could adapt it to machinery at every process more readily than wool—a more delicate, more complicated fibre-and more easily than flax and jute which were too stiff' (Mathias, 1983: 117).

${ }^{18} \mathrm{Admittedly,} \mathrm{'others'} \mathrm{and} \mathrm{'unknown'} \mathrm{are} \mathrm{residual} \mathrm{categories.} \mathrm{Our} \mathrm{results} \mathrm{presented} \mathrm{below} \mathrm{are} \mathrm{robust} \mathrm{to}$ the exclusion of the engines listed in these fields.
} 
distributions is to use entropy statistics. ${ }^{19}$ Entropy is a macroscopic measure that indicates the degree of randomness of a distribution. In our case, entropy indicators capture what might be called the macroscopic 'emerging properties' of the underlying micro-processes of variation and selection unfolding on the design space.

Maximum entropy occurs when all designers randomly move around in design space, which implies that all possible designs have an equal probability to be selected by designers. The analogy in physics is a gas in which particles randomly move around in state space. This hypothetical situation refers to a situation in which designers have not 'learnt' anything about the functional attributes of different designs (i.e. they lack an internal fitness function and/or an external selection environment to test the relative performance of the various designs). Non-random search in design space will typically lead to skewed distributions with some designs occurring with higher frequency than others. In this case, designers will not randomly move on the design space, but they will try to develop designs that fit closely the demands of users. For example, the application of a hill-climbing search heuristic will lead designers to introduce only locally optimal designs. An alternative or additional selection mechanism is provided by market competition that reveals the relative popularity of each design. Minimum entropy indicates maximum skewness and occurs when all designers opt for one and the same design. In this case, all designers are clustered in one 'corner' of the multi-dimensional design space. As such, entropy can be used as an indicator of technological standardization where a low entropy value is indicative of a dominant design (Frenken et al., $1999 b)$. Following the notation in (1), the $\mathrm{N}$-dimensional entropy of a product population is then given by (Theil, 1967, 1972):

$$
H\left(X_{1}, \ldots, X_{N}\right)=-\sum_{s \in S} p_{s} \cdot \ln p_{s}
$$

where $p_{s}$ is the relative frequency of design $s$ in the product population. Entropy is maximum when all $S$ possible designs have an equal frequency $p=1 / S$, which results in an entropy value of $H=-S \cdot(1 / S) \cdot \ln (1 / S)=\ln (S)$. Conversely, entropy is minimum when all products present in the population have the same design: $H=-1 \cdot \ln (1)=0$. A pure substitution process between an 'old' and a 'new' design will determine a growth of entropy from zero (when all users adopt the old design) to $\ln (2)$ when the two competing designs have a 50-50 market share, dropping to zero again (when all users have adopted the new design).

To understand to what extent the variety indicated by the entropy of the product population reflects the existence of complementarities among various design dimen-

\footnotetext{
${ }^{19}$ See also Frenken et al. (1999b), Frenken (2001), and Frenken and Nuvolari (2004) who discuss more in detail the concept of entropy and its possible uses in the analysis of technological evolution.

${ }^{20} 0 \cdot \ln (0) \equiv 0$. We use the natural logarithm to compute entropy (as in physics). Alternatively, one can use base two logarithm to express entropy in bits as in information theory (Theil, 1967, 1972; Langton, 1990).
} 
sions, we will make use of mutual information indicators (Frenken, 2001). Mutual information is given by (Theil, 1967, 1972; Langton, 1990):

$$
T\left(X_{1}, \ldots, X_{N}\right)=\sum_{s \in S} p_{s} \cdot \ln \frac{p_{s}}{\prod_{i=1}^{N} p_{s_{i}}}
$$

where $p_{s_{i}}$ stands for the marginal frequency of allele $s_{i}$ of dimension $i$ in the population. Mutual information indicates to what extent particular alleles along different dimensions co-occur in the technological designs of the product population. Statistically, mutual information indicates the degree of dependence between design dimensions. Mutual information is equal to zero when there is no dependence between any of the dimensions. In this case, the joint frequency of alleles corresponds exactly to the frequency that could be expected from the product of the marginal frequencies. When the product of marginal frequencies does not correspond to the joint frequency, there is dependence between dimensions and $T$ assumes a positive value. The greater the difference between the joint frequency and the product of marginal frequencies, the higher the value of the mutual information, the more alleles along particular dimensions co-occur in 'design families'.

The existence of local optima implies that specific alleles along one dimension typically co-occur with specific alleles along other dimensions, as by definition local optima have at least two alleles not in common. The more alleles are clustered in particular regions of the multi-dimensional design space, the higher the mutual information. A process of progressive differentiation in designs into design families clustered in the seven-dimensional design space, is thus indicated by a rising trend in entropy (variety) accompanied by a rising trend in mutual information (differentiation). Mutual information can be applied to any number of dimensions greater than one. Below, we will apply mutual information both to the seven-dimensional distribution and to each two-dimensional distribution covering two design dimensions. The seven-dimensional analysis captures the overall degree of differentiation, while the two-dimensional analysis individuates the couples of design dimensions in which differentiation has been most pronounced. The latter analysis allows one to discern the major interdependencies between each pair of dimensions. We will further apply the mutual information formula to the two-dimensional distributions constituted by one design dimension and the different sectors of application. In this way, we can analyse the dependence of sectors of application on each of the seven design dimensions to identify which design dimensions discriminate most between sectors of application.

As mentioned above, our main hypothesis not only holds that the product population evolved towards increasing variety (entropy) and differentiation (mutual information), but also that this increased variety is due to speciation of different designs becoming dominant in different selection environments.

To find out whether the variety of applications has indeed increased over time, we can compute for each moment in time the entropy of sectors of applications given by: 


$$
H(M)=-\sum_{m \in M} p_{m} \cdot \ln p_{m}
$$

where $p_{m}$ stands for the share of sector $m$ over the total product population. Computing the entropy of designs for each sector of application separately informs one about design variety within each sector $m$ (Theil, 1972):

$$
H_{m}\left(X_{1}, \ldots X_{N}\right)=-\sum_{s \in S} \frac{p_{s m}}{p_{m}} \cdot \ln \frac{p_{s m}}{p_{m}}
$$

where $p_{s m}$ stands for the share of design $s$ in sector $m$ over the entire product population $\left(\sum_{s \in S} p_{s m}\right.$ and $\left.\sum_{m \in M} p_{s m}=p_{s}\right)$. The average sectoral entropy of designs in the product population is then given by the weighted sum of entropy values at the sector level, where weights are based on the share of designs of each sector in the total product population $p_{m}$ (Theil, 1972: 19):

$$
\bar{H}_{M}\left(X_{1}, \ldots, X_{N}\right)=\sum_{m \in M} p_{m} \cdot H_{m}\left(X_{1}, \ldots, X_{N}\right)
$$

This formula expresses to what extent design variety is present at the level of each sector. $\bar{H}\left(X_{1}, \ldots, X_{N}\right)$ assumes a minimum value of zero when all sectors are completely dominated by a single design (which may or may not be the same design across sectors). The maximum possible value of $\bar{H}\left(X_{1}, \ldots, X_{N}\right)$ has been shown to be equal to $H\left(X_{1}, \ldots\right.$, $X_{N}$ ) (Theil, 1972: 65), and this value is obtained when design variety in each sector corresponds exactly to the design variety present at the level of the complete product population. Since we know that $0 \leq \bar{H}\left(X_{1}, \ldots, X_{N}\right) \leq H\left(X_{1}, \ldots, X_{N}\right)$, one can obtain a relative measure that indicates to what extent the overall variety in the product population is due to intra-sectoral or inter-sectoral variety, by dividing the average sectoral entropy by the total entropy:

$$
H_{M}^{\prime}\left(X_{1}, \ldots X_{N}\right)=\frac{\bar{H}_{M}\left(X_{1}, \ldots, X_{N}\right)}{H\left(X_{1}, \ldots X_{N}\right)}
$$

We call this measure the relative average sectoral entropy. When the relative average sectoral entropy is small, design variety in the product population is mainly due to inter-sectoral variety and when the relative average sectoral entropy is large, design variety in the product population is mainly due to intra-sectoral variety. In the former case (for a given level of variety in the total product population) we have a high degree of speciation, while in the latter case we have a low degree of speciation.

\section{Technological evolution in early steam engine development}

Let us turn the attention to the empirical results for the population of steam engine designs. Throughout the following, we will consider three-year moving averages of the yearly values of entropy and mutual information in order to smooth short-term fluctuations. This transformation does not affect in any way our conclusions. 


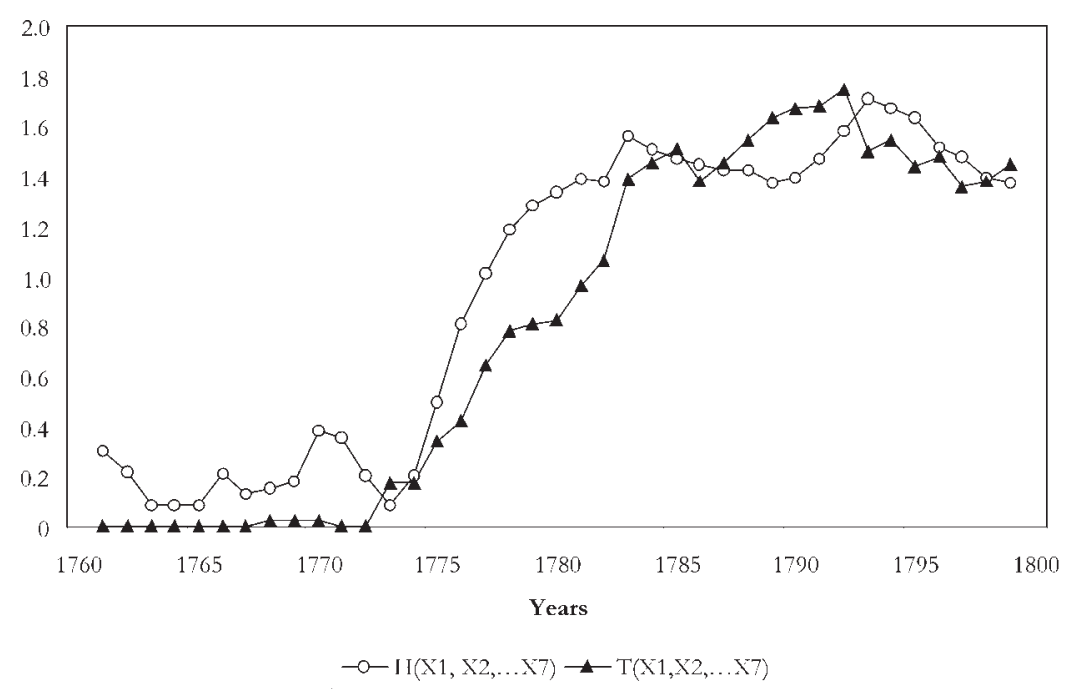

Figure 3 Entropy $H\left(X_{1}, \ldots, X_{7}\right)$ and mutual information $T\left(X_{1}, \ldots, X_{7}\right)$ of the product population.

\subsection{Variety and differentiation}

In Figure 3 we report the behaviour of the seven-dimensional entropy $H\left(X_{1}, \ldots, X_{7}\right)$ and of the mutual information $T\left(X_{1}, \ldots, X_{7}\right)$ of the product population. The results clearly indicate that both variety (entropy) and differentiation (mutual information) have increased rapidly from the year 1774 . At the time the Watt reciprocating engine became a popular design next to the Newcomen reciprocating engine. Thus, starting from the mid-1770s, the development of the steam engine has been characterized by the introduction of new alleles along several dimensions, which accounts for the growth of variety. Inventive activity also led to a process of differentiation into an increasing number of design families. Thus, inventions in separate dimensions have been combined in such a way that the product population increasingly clustered in some specific corners of the multi-dimensional design space.

Closer inspection of Figure 3 reveals that, during the 1770s and the early 1780s, the rise in entropy precedes increases in mutual information. In our interpretation, this suggests that, in a first phase, combinations of new alleles were attempted, leading to increases in variety. However, a number of these new combinations did not reach an adequate level of fitness, so we observe that, with some delay, mutual information 'catches up' with entropy. We have first a phase of exploration and discovery of new areas of the landscape followed by concentration in some points that may well represent local optima. The 'levelling off phase' starting in the late 1780 s seems to indicate a stabilization of the pattern of differentiation that had emerged earlier.

Figure 4 displays the evolution of the pair-wise mutual information. These results are informative on the nature of the technological interdependencies among design 


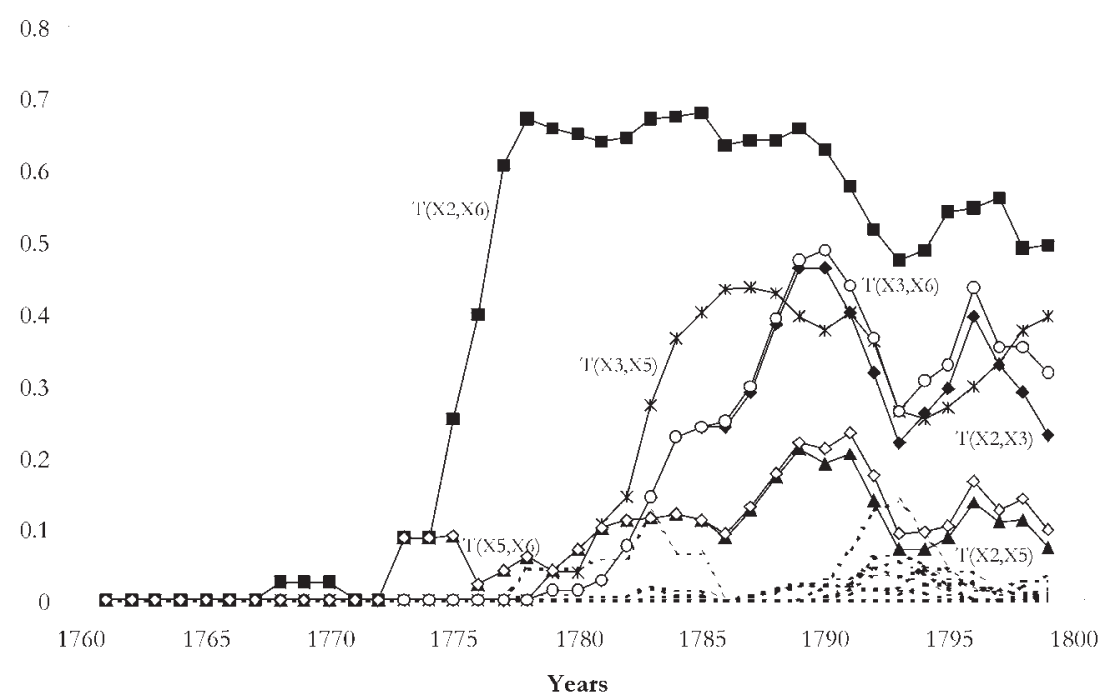

Figure 4 Two-dimensional mutual information $\left[T\left(X_{1}, X_{2}\right), \ldots, T\left(X_{6}, X_{7}\right)\right]$ of the product population.

dimensions that were responsible for the process of differentiation into distinct design families. The highest mutual information values are reached by the pair $T\left(X_{2}, X_{6}\right)$, which reflects the interdependency between the dimensions with/without condenser and open/closed top cylinder. Separate condensation and the closed top cylinder are the two salient features distinguishing Watt type of engines (0100010) from Newcomen atmospheric engines without condensation and open top (0000000). Importantly, high values of $T\left(X_{2}, X_{6}\right)$ are not a temporary phenomenon but continue during the whole period considered. These results thus indicate the emergence of a pattern of continuing differentiation rather than technological substitution between Watt and Newcomen engine designs beginning in the early 1770s.

In Figure 4, couples that did not reach high levels of mutual information are represented by thin dotted lines, and couples with relatively high levels of mutual information are represented by continuous lines with markers. What becomes clear from these results is that the interdependencies among design dimensions are limited to four dimensions: $X_{2}, X_{3}, X_{5}$ and $X_{6}$, respectively, with/without condenser, single/double acting, reciprocating/rotary/water returning, and open/closed top. As explained above, dimensions $X_{2}$ and $X_{6}$ differentiate Newcomen and Watt engines. Dimensions $X_{3}$ and $X_{5}$ concern different solutions to deliver particular types of motion. Double action was a typical feature of Watt rotary engines (0110110), while Newcomen engines delivering rotary motion either returned a stream over a waterwheel (0000200) or they acted directly by means of a crank and flywheel (0000100). From the early 1790s, Newcomen rotary engines with two cylinders (0000101) also became a popular solution constituting yet another differentiation. 


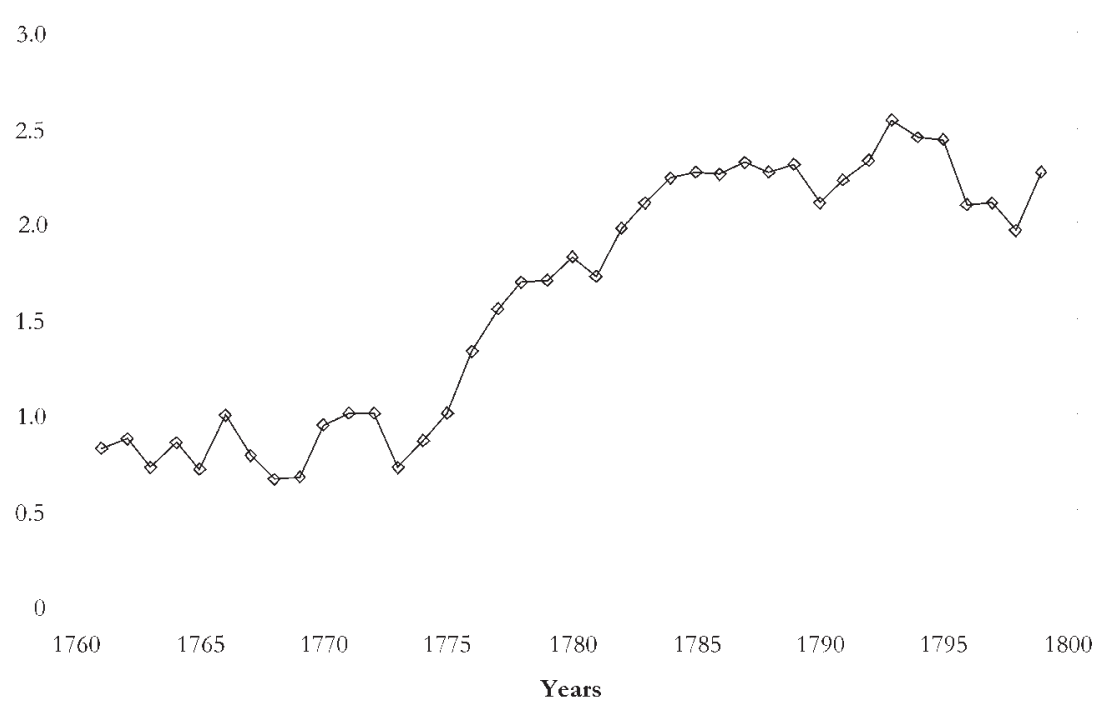

Figure 5 Entropy $H(M)$ of application sectors.

It is interesting to note that within the two main design families constituted by Newcomen and Watt engine designs, a process of further differentiation took place associated with the need to adapt the engine to the functional requirements of the sector in which it was employed. In particular, the type of motion delivered by the engine exerted an important influence in determining differentiation among engine designs. Whereas Watt rotary engines employed double action, Newcomen rotary engines did not make use of that feature.

There are three designs, the Hornblower, Symington and Trevithick engines, which cannot be ascribed neither to the Newcomen or to the Watt family and constitute three additional groups. The Symington engine (0100000) represents a hybrid solution between a Newcomen and a Watt engine, whereas Trevithick (1010110) and Hornblower (0101011) engines embody design features (high pressure and compounding, respectively) that would characterize nineteenth-century developments. Their impact in terms of diffusion during the late eighteenth century, however, has been quite small (a total of respectively 18 and 20 engines were erected up to 1800).

\subsection{Variety and speciation}

Figure 5 charts the one-dimensional entropy $H(M)$ for application sectors using the shares of sectors in each year. The figure shows the growing extension of the range of possible applications of the steam engine. In particular, the range of possible of applications of early steam engines grew during the 1770s and 1780s, stabilizing from the late 1780 s. In fact, up to the early 1770 s, steam engines were only adopted in the mining and metalworking sectors (especially in iron blast furnaces, see Hyde, 1977: 


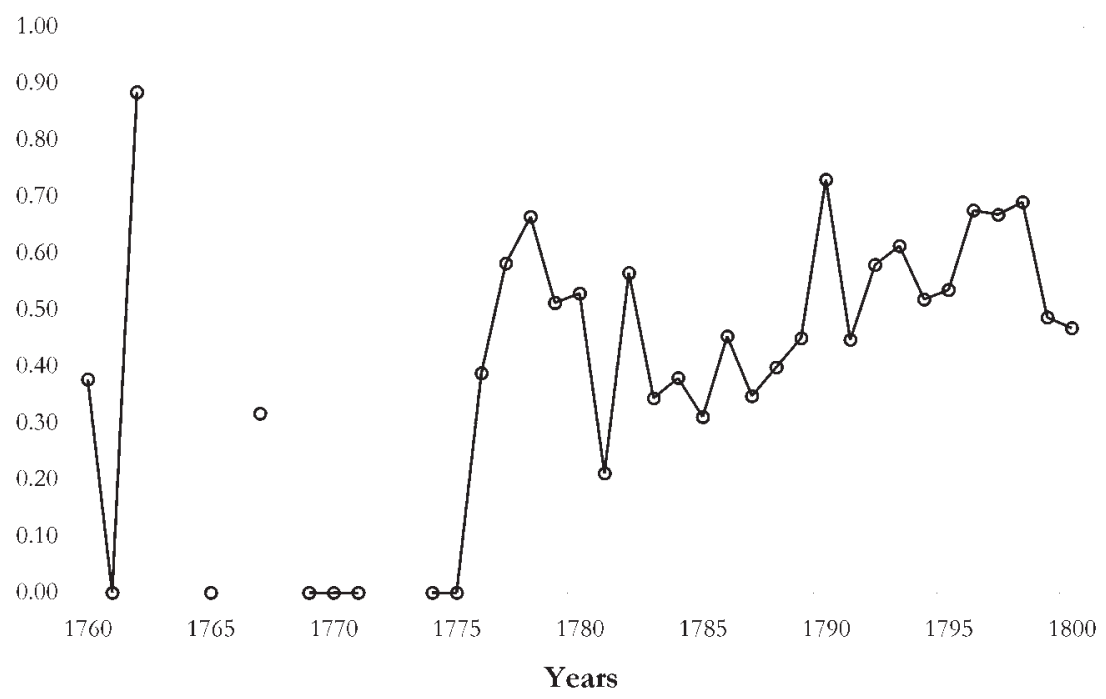

Figure 6 Relative average sectoral entropy $\bar{H}_{M}^{\prime}\left(X_{1}, \ldots, X_{N}\right)$.

71-75), while thereafter the technology begun to be adopted in a host of new applications such as textiles, foods and water-working.

It remains to be established whether the rise in design variety (Figure 3 ) and the rise in the variety of sectors in which steam engines were applied (Figure 5) were coupled in a process of speciation. Figure 6 displays the relative average sectoral entropy $\bar{H}_{M}^{\prime}\left(X_{1}, \ldots, X_{N}\right)$. Recall that the lower this value, the higher the extent to which application sectors are dominated by few designs. Before $1775 \bar{H}_{M}^{\prime}\left(X_{1}, \ldots, X_{N}\right)$ is mostly equal to zero, ${ }^{21}$ which reflects the fact that the two engines constructed in the period, the Newcomen reciprocating engine and the Newcomen water-returning engine, established themselves in distinct niches (respectively coal mining and metal working). From 1775 onwards the relative average sectoral entropy is characterized by a phase of steady growth, followed by what seems to be a fluctuating behaviour, revealing that application sectors were characterized by the presence of different designs. In this phase, the design variety in the total product population is due both to intra-sectoral variety (reflecting the existence of multiple local optima in an application sector) and to inter-sectoral variety (reflecting the specialization of different designs in distinct application sectors).

In our interpretation, the co-existence of intra- and inter-sectoral variety indicates that in most sectors different designs were capable of delivering satisfactory levels of performance due to the existence of local optima. Thus, design variety in most sectors is

\footnotetext{
${ }^{21}$ For a few years both the value of the average sectoral entropy and of the entropy of the total product population are equal to zero, indicating that the same type engine was constructed in all sectors. These cases are represented by missing values of the relative average sectoral entropy.
} 
Table 3 Specialization of engine designs in application sectors for the period 1760-1800

\begin{tabular}{|c|c|c|c|c|c|c|c|c|c|c|c|}
\hline Engines & String & Coal & $\begin{array}{l}\text { Other } \\
\text { mining }\end{array}$ & Cotton & $\begin{array}{l}\text { Wool } \\
\text { and other } \\
\text { textiles }\end{array}$ & Metalworking & Foods & $\begin{array}{l}\text { Waterworks } \\
\text { and canals }\end{array}$ & Others & Unknown & Number \\
\hline Newcomen (reciprocating) & $(0000000)$ & 0.22 & -0.01 & -0.73 & -0.72 & -0.25 & -0.84 & -0.11 & -0.60 & 0.16 & 630 \\
\hline Pickard (Newcomen rotary) & $(0000100)$ & 0.08 & -0.74 & -0.16 & 0.23 & 0.17 & 0.25 & -0.63 & 0.09 & -0.51 & 107 \\
\hline Watt (reciprocating) & $(0100010)$ & -0.34 & 0.54 & -1 & -1 & 0.12 & -0.79 & 0.61 & -0.28 & -0.37 & 152 \\
\hline Newcomen (rotary two cyl.) & $(0000101)$ & -0.12 & -0.59 & 0.22 & 0.05 & -0.51 & -0.27 & 0.51 & 0.47 & 0.06 & 31 \\
\hline Hornblower & $(0101011)$ & -1 & 0.60 & -1 & -1 & -0.28 & -0.01 & -1 & 0.41 & 0.32 & 18 \\
\hline Watt (rotary, double acting) & $(0110110)$ & -0.62 & -0.86 & 0.51 & 0.44 & 0.11 & 0.49 & -0.45 & 0.39 & -0.13 & 316 \\
\hline Symington & $(0100000)$ & 0.01 & 0.09 & -1 & 0.26 & -1 & 0.56 & -1 & 0.36 & -1 & 20 \\
\hline Trevithick's puffer & $(1010110)$ & -1 & 0.78 & -1 & -1 & -1 & -1 & -1 & -1 & -1 & 6 \\
\hline Newcomen (water returning) & $(0000200)$ & -0.14 & -1 & 0.37 & 0.46 & 0.39 & -0.03 & -1 & -0.14 & -0.04 & 76 \\
\hline Watt (water returning) & $(0100210)$ & -1 & -0.23 & -0.14 & -1 & 0.65 & 0.16 & -1 & 0.63 & -1 & 13 \\
\hline Number & & 615 & 170 & 140 & 40 & 135 & 77 & 57 & 96 & 39 & 1369 \\
\hline
\end{tabular}

Values $>0$ indicating a relative specialization of a particular engine design in a specific sector are in bold. The last column and the last row report the total number of engines. 
positive, yet substantially lower than the design variety at the level of the product population as a whole, showing a certain degree of speciation of different designs into distinct application sectors.

In order to trace the precise pattern of specialization of engine designs in application sectors, we have computed an indicator of (relative) technological specialization similar to the revealed technological advantage (RTA) index used in the patent literature (Soete and Wyatt, 1983). The results are presented in Table 3. Our indicator of specialization, $S P$, is computed as follows:

$$
S P=\frac{\sigma_{s m}-1}{\sigma_{s m}+1}
$$

with $\sigma_{s m}=\left(p_{s m} / p_{m}\right) / p_{s}$ where in this case the shares $p_{s}$ and $p_{s m}$ are computed using all the engines constructed during the period 1760-1800. The $S P$ formula transforms $\sigma_{s m}$ in an index symmetric between -1 and 1 . A value of the indicator larger than zero indicates that a particular engine design is (relatively) specialized in the application sector in question; conversely, values lower than zero stand for (relative) despecialization. The table shows that some sectors are dominated by only one or two designs (coal mining, and waterworks and canals), while other sectors have witnessed a considerable design competition, in particular between the various Newcomen and Watt types of engines. To understand better the determinants of speciation that gave rise to inter-sectoral variety, we are interested in the design dimensions that best discriminate between sectors of application. Figure 7 displays the mutual information between each individual design dimension and the dimension of sector of application. The dependence of each design dimension on the sectors of application shows pronounced differences. Four out of seven design dimensions are powerful in discriminating among application sectors $\left(X_{2}, X_{3}, X_{5}\right.$ and $\left.X_{6}\right)$. In accordance with the NK-model, these dimensions are precisely those that exhibit the strongest internal design interdependencies (Figure 5), and thus create the trade-offs among the various functions of the technology.

The highest value in Figure 7 is found for the type of motion delivered by the engine $T\left(X_{5}, M\right)$. This result indicates that sectors of application differed primarily in the type of motion that was required. Reciprocating engines were primarily useful in coal mines, other mines and waterworks for lifting purposes. Rotary motion and water returning motion were generally required in textiles and food sectors. The values of $T\left(X_{2}, M\right)$ and $T\left(X_{6}, M\right)$, representing with/without condenser and open/closed top distinguishing Newcomen from Watt engines, move closely together and have discriminatory power among application sectors. This can be explained by the superior fuel-efficiency performance of Watt engines compared to Newcomens. In sectors where coal was relatively cheap, such as coal mining, Newcomen engines dominated while in other sectors Watts became the leading technology. The double-acting motion delivered by the Watt rotary engines was superior in terms of smoothness to other single-acting types of rotary motion. High values for $T\left(X_{3}, M\right)$ indeed suggests that Watt rotary engines rapidly established dominance in sectors like cotton, foods, paper mills and 


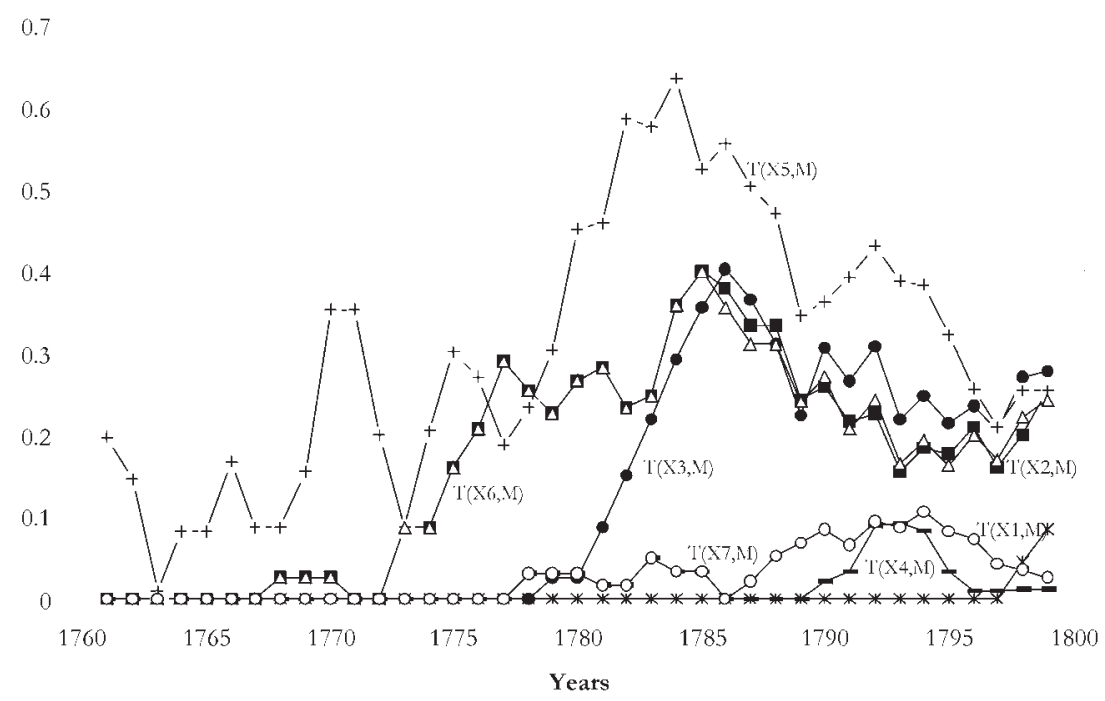

Figure 7 Mutual information design dimensions/sectors, $T\left(X_{1}, M\right), \ldots, T\left(X_{7}, M\right)$.

potteries where the smoothness of motion was a crucial performance requirement. In other sectors, single-acting rotary engines were typically used. Note that the values of $T\left(X_{2}, M\right), T\left(X_{6}, M\right), T\left(X_{5}, M\right)$ and $T\left(X_{3}, M\right)$, after a phase of rapid growth, exhibit a 'falling off' phase starting approximately in the late 1780s. In our interpretation this is due to the fact that some applications were indeed 'opened' by a specific engine designs, but this dominance did not last for long. With some delay, other types of engines entered the application sectors leading to lower values of mutual information. ${ }^{22}$ To repeat, the pattern of specialization was not perfect.

\section{Towards a re-examination of early steam engine history}

Our major result holds that the Watt engine should not to be considered as a linear successor' of the Newcomen engine but rather as a speciation event that opened up new applications. This result supports studies that pointed to the continuing attraction of the Newcomen engine technology. In his famous Treatise on the Steam Engine published in 1827, John Farey already noted that for pumping purposes in coal mining, Newcomen engines were still 'universally employed' (Farey, 1827: 307). Dionysius Lardner made a similar remark as late as 1840 (Cardwell, 1963: 54). The continued success of the Newcomen engines can be ascribed to its cost and maintenance

\footnotetext{
${ }^{22}$ The decline of $T\left(X_{5}, M\right)$ is to be ascribed to the progressive adoption of rotary engines in mining (for winding ore) and metalworking sectors. The decline of $T\left(X_{2}, M\right), T\left(X_{6}, M\right)$ and $T\left(X_{3}, M\right)$ instead reflects the increasing competition between Watt and the various rotary versions of the Newcomen engine in textiles and other manufacturing applications requiring rotary motion.
} 
advantages. Von Tunzelmann (1978: 75) has estimated that prices of Newcomen engines ranged between 75 and $95 \%$ of those of Watt engines of the same power. ${ }^{23}$ In addition, Newcomen engines were also characterized by much lower maintenance costs. Hence, in areas where coal was cheap enough, the Newcomen engine had an important advantage due to its lower costs of installation and maintenance. Besides being cheaper in erection and maintenance, the Newcomen engine had the advantage of being well within the reach of the engineering capabilities of the time, whereas the Watt engine imposed very compelling requirements on the degree of accuracy of its various components, in particular the boring of the cylinder. ${ }^{24}$ This points to the existence of a fundamental trade-off concerning fuel-efficiency versus simplicity of construction and maintenance. ${ }^{25}$

The trade-off between fuel-efficiency and costs becomes clear from the diffusion pattern of the Watt reciprocating engine in mining districts located in areas where the high price of coal had so far prevented the widespread use of the Newcomen engine. The most important of these districts is Cornwall. ${ }^{26}$ However, even in areas where coal prices were relatively high, the Watt engine faced competition from new engine designs entering and competing quite successfully. In Cornwall, for example, the Watt reciprocating engine (0100010) faced competition from the compound double-cylinder engine developed by Hornblower (0101011) in the early 1780s. According to contemporary accounts, the two engines delivered a very similar performance in terms of fuel efficiency (Farey, 1827: 387-393). One has to add here that the diffusion of the Hornblower engine was severely limited by the legal actions of Boulton and Watt who claimed that the engine was infringing their patent, deterring in this way a number of potential buyers of the Hornblower engine. Recent research has argued that Boulton and Watt allegations of infringement were unwarranted (Torrens, 1994).

Interestingly enough, there was also an attempt of developing an 'hybrid' engine combining the simplicity of Newcomen with the fuel-efficiency of Watt. This was the 'improved atmospheric engine' patented by Symington in 1787 (0100000). Unfortunately, we have scant information on this engine (especially on its fuel efficiency compared to Watt). We know that about twenty engines of this type were erected

\footnotetext{
${ }^{23}$ According to Andrew (1995), Newcomen and Watt engines had the same costs for equal power and for a 'similar engineering standard'. However, one has to take into account that Newcomen engines were normally constructed adopting a lower engineering standard than Watts. So the figures proposed by von Tunzelmann (1978) can be considered more representative of a typical situation.

${ }^{24}$ Watt's invention of the separate condenser would hardly have been so successful without the new technique for boring cylinders developed by John Wilkinson in 1774 (von Tunzelmann, 1978: 19).

${ }^{25}$ Joseph Bramah stated that the Newcomen engine detained over Watt 'an infinite superiority in terms of simplicity and expense'. John Smeaton, one of the leading engineers of the time, considered that the Watt engine demanded too higher standards for construction and maintenance (Harvey and DownsRose, 1980: 22-23).

${ }^{26}$ On the diffusion of the Boulton and Watt engine in Cornwall, see Tann (1996).
} 
(mainly in Scotland) and that they generally proved rather successful. ${ }^{27}$ Some historians of technology have dismissed Symington simply as a 'schemer' who tried to circumvent Watt's patent (Dickinson and Jenkins, 1927: 318; Farey, 1827: 656). In our judgement, the prolonged co-existence of Watt and Newcomen engines instead suggests that Symington's attempt to merge the two separate design trajectories of Newcomen and Watt was genuinely aimed at combining the merits of both engines.

A second major result of our analysis points to another speciation event concerning the dimension of the quality of motion. We consider the development of Watt's double-acting rotary engine as a speciation event rather than a 'linear' successor of earlier technologies. The main effect of the introduction of the Watt double-acting rotary engine in 1780 has been the opening up of new industrial applications to steam power technology, in particular cotton and foods. Although Watt's inventions to supply rotary motion were highly celebrated (Dickinson and Jenkins, 1927), they cannot by any means be considered as definitive. In 'older' industrial applications, Watt doubleacting rotary engines did not achieve anything close to dominance. In metalworking, for example, Newcomen water-returning engines remained widely used (see again Table 3, which illustrates the pattern of relative specialization of the engine designs). Furthermore, in textiles some adopters still preferred Newcomen rotary or waterreturning engines over Watt rotary engines. We are aware of many cases of unsatisfactory performance of Watt rotary engines in textile mills compared to water-returning designs (Hills, 1970: 179-186). ${ }^{28}$ Concerning Newcomen engines delivering rotary motion by means of the crank and flywheel arrangement (0000100), John Farey wrote:

About the years 1790 to 1793 , when steam mills began to be introduced into all large manufacturing towns, with Mr. Watt's improved engines, great numbers of atmospheric engines were also made for turning mills, particularly in districts were coals were cheap. . . It is still a very common practice, in districts where coals are cheap to work machinery by Newcomen's engines. (Farey, 1827: 422)

[These atmospheric engines] answered tolerably well for some purposes, which did not require a very regular motion, such as drawing coals out of mines, grinding corn, crushing seeds ... (ibid.: 658)

However, in applications, most notably cotton spinning, where a very smooth motion was required, the development of the Watt double-acting engine in 1784 initially led to an almost complete market dominance. In response, design activity in Newcomen engines focused on ways to mimic direct double acting motion. A solution was found in the use of two cylinders in Newcomen engines that acted alternatively on

\footnotetext{
${ }^{27}$ On the Symington engine, see Harvey and Downs-Rose (1980: ch. 3).

${ }^{28}$ Well into the nineteenth century, many contemporary engineers believed that the rotary drive produced by a water returning engine was much more regular and, in the end, 'better' than the one delivered by a Watt rotary engine (von Tunzelmann, 1978: 142-143).
} 
the same crank (0000101). The leading engineers in the development of this technical solution were Bateman and Sherrat and Francis Thompson. According to Musson and Robinson (1969: 408), in the Manchester textile district, in the 1790s this type of engines were widely adopted. Again, the older Newcomen technology was able to adapt itself to new selective pressures, so that the dominance of Watt engine technology was halted. ${ }^{29}$

Although traditional accounts have also emphasized the role of Watt's inventions in opening up new application sectors to steam power, these accounts most likely underestimated the fierce competition faced by Watt engines. Of course, one of the major determinants behind the competition were the high royalties that adopters of Boulton and Watt engines had to pay. However, in our view, technological factors should also to be taken properly into account. Watt engines were far from being a complete and satisfactory solution to various user needs, the main problem being in most cases the much too high degree of engineering sophistication required by the Watt engine in its various versions. ${ }^{30}$ Jennifer Tann describes the choice of engine adopters in these terms:

[W] hen information was more accessible and there were more engines to be seen, potential adopters quite frequently carried out a simple comparative cost/benefit analysis. From their limited inputs of information it was clear to them that the most rational answer was not necessarily to purchase a Boulton and Watt engine. Indeed at some locations it would have been a folly. (Tann, 1979: 181)

So, together with attempts at circumventing Watt's patent, in order to skim off some of the profits that Boulton and Watt were reaping, there were also more genuine attempts at improving the 'fitness' of the engine in various application sectors. ${ }^{31}$ Interestingly enough, with hindsight, one can identify two main design trajectories aimed at improving the various functional attributes of the steam engine. The first trajectory consisted in trying to expand on the Newcomen design, by exploiting its virtues of simplicity and reliability. This was essentially the direction taken by Symington, Pickard, Thompson, and Bateman and Sherratt. ${ }^{32}$ In a sense, this can bee

\footnotetext{
${ }^{29}$ Unfortunately most of the double cylinder engines erected by Bateman and Sherrat have left no trace in the records (Musson and Robinson, 1969: 410). Hence, our dataset is likely to underestimate the contribution of this type of engine to variety and differentiation.

${ }^{30}$ Concerning the Watt rotative engine, Hills (1989: 75) aptly comments: 'The world of mechanical engineering was then in its infancy and the Boulton and Watt rotative engine demanded higher standards in its manufacture than anything in its scale at the time.'

${ }^{31}$ Note that in our conceptualization of the design space, Watt 'pirate' engines, even when incorporating some minor modifications as in the case of the Bull engine, are counted as Watt engines, so that they do not contribute to variety and differentiation.
}

${ }^{32} \mathrm{~A}$ very good overview of the producers of 'improved' Newcomen engines in Britain in the late eighteenth century is contained in Tann (1979). 
seen as a sort of 'sailing ship effect', although we should take into account that it was not so much a 'defensive', but rather an 'offensive' action. The Newcomen engine was not threatened by Watts in its main application domain (coal mining). In fact, the improvements were aimed at expanding the range of application of the original design. The second trajectory, instead, was the attempt of finding out new viable designs. This is the direction taken by Hornblower and Trevithick, whose designs are precursors of nineteenth century developments. Thus, rather than a 'linear' process of introduction of novel features and replacement of old designs, the early development of the steam engine seems to have been characterized by the formation of a variety of design families, each of them aimed at satisfying a rather specific set of user needs. A similar interpretation, stressing the role of persistent variety, has been also proposed by von Tunzelmann: ${ }^{33}$

It is misleading to see the pattern of progress [in steam engine technology] as linear and inevitable: in explaining the direction and the chronology of 'technical progress' in the economist's sense, it is vital to keep this diversity in mind. (von Tunzelmann, 1978: 24)

\section{Concluding remarks}

In this paper we have presented an interpretative framework for the analysis of patterns of technological evolution. We have applied this framework to the case of the early development of the steam engine. In the second half of the eighteenth century, the introduction of Watt's separate condenser and Pickard's adoption of the crank and the flywheel extended the possible range of applications of steam engine technology. As suggested by Saviotti (1996) and Levinthal (1998) the adaptation of a technology to a new application domain (in so far the new domain imposes specific requirements on the functional attributes of the technology) is akin to a 'speciation' event in biology. Accordingly, the adaptation of the technology to the new application sector requires the introduction of a number of design modifications. The modified design is then subject to a distinctive set of selection pressures. This is likely to trigger a new localized search process in the neighbourhood of the new design configuration. Over time, divergent evolutionary trajectories may be expected to unfold.

Our analysis of the evolution of early steam engine technology broadly confirms these insights. In our interpretation the (imperfect) specialization of designs in different users' niches was the outcome of a process of localized search in response to sector-specific functional requirements. Interestingly enough, this process had a long-lasting impact on the evolution of steam engine technology throughout the nineteenth century. In this period, the overall pattern of technical change in steam engines has continued to be characterized by differentiated trajectories of technological development. Notably, the rates of technological change along these trajectories were

\footnotetext{
${ }^{33} \mathrm{An}$ analogous view is also sketched in Cragg (1989).
} 
highly uneven. ${ }^{34}$ One of main factors underlying this pattern were the teething difficulties in transferring innovations matured along a specific trajectory to other application sectors.

Even after the scientific formulation of the law of thermodynamics in the 1850s, which, without any doubt, provided a sound basis for the development of 'generic' technological solutions, sector-specific selection biases continued to affect the evolution of steam technology (Hunter, 1985: 436-437). Interestingly enough, Gustave Adolphe Hirn, one of the leading pioneers of scientific thermodynamics, remarked that the formulation of a fully fledged theory of the steam engine had been of little help in actual steam engineering developments: sector-specific functional requirements dictated too many features of the actual design configuration (Cardwell, 1994: 314). According to Hunter (1985), technological evolution remained highly localized even in the period in which scientific knowledge rapidly expanded in the realm of thermodynamics. As we have shown in this paper, this pattern of localized technological progress along distinct trajectories set in at an early stage in the evolution of steam power technologies.

\section{Acknowledgements}

We are grateful to John W. Kanefsky for providing us with the updated version of his dataset of British steam engines. Nick von Tunzelmann has given us valuable suggestions throughout the preparation of this paper. The present version has also greatly benefited from the comments of Carolina Castaldi, Bart Verspagen, Geert Verbong, Ron Boschma and of two anonymous referees. Earlier drafts were presented at the second European Meeting on Applied Evolutionary Economics (Vienna University of Economics and Business Administration, September 2001) and at seminars at SPRU (University of Sussex, January 2002) and at CESPRI (Bocconi University, Milan, May 2002). We would like to thank the participants at these meetings (in particular Arnulf Grübler, Keith Pavitt, Stefano Brusoni, Franco Malerba, Roberto Fontana and Stefano Breschi) for astute comments and enjoyable discussions.

\section{Address for correspondence}

Koen Frenken, Urban and Regional research centre Utrecht (URU), Faculty of Geosciences, Utrecht University, PO Box 80115, 3508 TC, Utrecht, The Netherlands. Email: k.frenken@geog.uu.nl.

Alessandro Nuvolari, Eindhoven Centre for Innovation Studies (ECIS), Eindhoven University of Technology, PO Box 513, 5600 MB, Eindhoven, The Netherlands. Email: a.nuvolari@tm.tue.nl.

\footnotetext{
${ }^{34}$ Consistently with our findings, Halsey (1981) individuates five distinct design families characterized by 'localized' technological progress in early nineteenth century steam engine technology. On the uneven rates of technological change among different application sectors in nineteenth-century steam engineering, see Nuvolari and Verspagen (2003).
} 


\section{References}

Altenberg, L. (1994), 'Evolving better representations through selective genome growth,' in Proceedings of the IEEE World Congress on Computational Intelligence, Part 1. IEEE: Piscataway NJ, pp. 182-187.

Altenberg, L. (1995), 'Genome growth and the evolution of the genotype-phenotype map', in W. Banzhaf and F. H. Eckman (eds), Evolution and Biocomputation. Springer-Verlag: Berlin and Heidelberg, pp. 205-259.

Andrew, J. (1995), 'The costs of eighteenth century steam engines,' Transactions of the Newcomen Society, 66, 77-95.

Bradshaw, G. (1992), 'The airplane and the logic of invention,' in R. Giere (ed.), Cognitive Models of Science. University of Minnesota Press: Minneapolis, pp. 239-250.

Cardwell, D. S. L. (1963), Steam Power in the Eighteenth Century. A Case Study in the Application of Science. Sheed \& Ward: London.

Cardwell, D. S. L. (1971), From Watt to Clausius. Heinemann: London.

Cardwell, D. S. L. (1994), The Fontana History of Technology. Harper: London.

Cragg, C. B. (1989), 'The evolution of the steam engine,' in K. Hahlweg and C. A. Hooker (eds), Issues in Evolutionary Epistemology. SUNY: Albany, NY, pp. 313-356.

Dickinson, H. W. (1938), A Short History of the Steam Engine. Cambridge University Press: Cambridge.

Dickinson, H. W. and R. Jenkins (1927), James Watt and the Steam Engine. Clarendon Press: Oxford.

Dosi, G., D. A. Levinthal and L. Marengo (2003), 'Bridging contested terrain: linking incentive based and learning perspectives on organizational evolution,' Industrial and Corporate Change, $12,413-436$.

Farey, J. (1827), A Treatise on the Steam Engine. Historical, Practical and Descriptive. London (2nd edn David \& Charles: Newton Abbot, 1971).

Fisher, J. C. and R. H. Pry (1971), 'A simple substitution model of technical change,' Technological Forecasting and Social Change, 3, 75-81.

Frenken, K. (2001), 'Understanding product innovation using complex systems theory', Ph.D. thesis, University of Amsterdam and University of Grenoble.

Frenken, K., L. Marengo and M. Valente (1999a), 'Interdependencies, near-decomposability and adaptation,' in T. Brenner (ed.), Computational Techniques for Modelling Learning in Economics. Kluwer: Boston, MA, pp. 209-244.

Frenken, K., P. P. Saviotti and M. Trommetter (1999b), 'Variety and niche creation in aircraft, helicopters, motorcycles and microcomputers,' Research Policy, 28, 469-488.

Frenken, K. and A. Nuvolari (2004), 'Entropy statistics as a framework to analyse technological evolution,' in J. Foster and W. Hölzl (eds), Applied Evolutionary Economics and Complex Systems. Edward Elgar: Cheltenham.

Gavetti, G. and D. Levinthal (2000), 'Looking forward and looking backward: cognitive and experiential search,' Administrative Science Quarterly, 45, 113-137. 
Halsey, H. I. (1981), 'The choice between high-pressure and low-pressure steam power in America in the early nineteenth century,' Journal of Economic History, 41, 723-744.

Harvey, W. S. and G. Downs-Rose (1980), William Symington. Inventor and Engine Builder. Northgate: London.

Hills, R. L. (1970), Power in the Industrial Revolution. Manchester University Press: Manchester.

Hills, R. L. (1989), Power from Steam. Cambridge University Press: Cambridge.

Hotelling, H. (1929), 'Stability in competition,' Economic Journal, 39, 41-57.

Hunter, L. C. (1985), A History of Industrial Power in the United States, 1780-1930: Steam Power. University Press of Virginia: Charlottesville.

Hyde, C. K. (1977), Technological Change and the British Iron Industry 1700-1870. Princeton University Press: Princeton, NJ.

Kanefsky, J. W. (1979), 'The Diffusion of Power Technology in British Industry, 1760-1870, Ph.D. thesis: University of Exeter.

Kanefsky, J. W. and J. Robey (1980), 'Steam engines in 18th-century Britain: a quantitative assessment,' Technology and Culture, 21, 161-186.

Kauffman, S. A. (1993), The Origins of Order. Self-organization and Selection in Evolution. Oxford University Press: New York and Oxford.

Kauffman, S. A. and W. G. Macready (1995), 'Technological evolution and adaptive organizations,' Complexity, 1, 26-43.

Kauffman, S. A., J. Lobo and W. G. Macready (2000), 'Optimal search on a technology landscape,' Journal of Economic Behavior and Organization, 43, 141-166.

Lancaster, K. J. (1979), Variety, Equity and Efficiency. Columbia University Press: New York.

Langton, C. G. (1990), 'Computation at the edge of chaos', Physica D, 42, 12-37.

Levinthal, D. A. (1997), 'Adaptation on rugged landscapes', Management Science, 43, 934-950.

Levinthal, D. A. (1998), 'The slow pace of rapid technological change: gradualism and punctuation in technological change,' Industrial and Corporate Change, 7, 217-247.

Marengo, L., G. Dosi, P. Legrenzi and C. Pasquali (2000), 'The structure of problem-solving knowledge and the structure of organizations,' Industrial and Corporate Change, 9, 757-788.

Mathias, P. (1959), The Brewing Industry in England, 1700-1830. Cambridge University Press: Cambridge.

Mathias, P. (1983), The First Industrial Nation, 2nd edn. Methuen: London.

Merton, R. K. (1938), Science, Technology and Society in Seventeenth Century England. Harper: New York.

Musson A. E. and E. H. Robinson (1969), Science and Technology in the Industrial Revolution. Manchester University Press: Manchester.

Nijkamp, P., P. Rietveld and H. Voogd (1990), Multicriteria Evaluation and Physical Planning. North-Holland: Amsterdam.

Nuvolari, A. and B. Verspagen (2003), " "Unravelling the duty": Lean's Engine Reporter and the development of the Cornish steam engine,' paper presented at the 2003 Annual Conference of the Economic History Society, Durham, UK, 4-6 April 2003. 
Rivkin, J. W. (2000), 'Imitation of complex strategies', Management Science, 46, 824-844.

Rolt, L. T. C. and J. S. Allen (1977), The Steam Engine of Thomas Newcomen. Hartington: Moorland.

Rosenberg, N. (1976), Perspectives on Technology. Cambridge University Press: Cambridge.

Saviotti, P. P. (1996), Technological Evolution, Variety and the Economy. Edward Elgar: Cheltenham and Brookfield.

Saviotti, P. P. and J. S. Metcalfe (1984), 'A theoretical approach to the construction of technological output indicators,' Research Policy, 13, 141-151.

Simon, H. A. (1969), The Sciences of the Artificial. MIT Press: Cambridge MA and London.

Simon, H. A. (2002), 'Near decomposability and the speed of evolution,' Industrial and Corporate Change, 11, 587-599.

Soete, L. G. and S. M. E. Wyatt (1983), 'The use of foreign patenting as an internationally comparable science and technology output indicator,' Scientometrics, 5, 31-54.

Tann, J. (1979), 'Makers of improved Newcomen engines in the late 18th century,' Transactions of the Newcomen Society, 50, 181-192.

Tann, J. (1996), 'Riches from copper: the adoption of the Boulton and Watt engine by Cornish mine adventurers', Transactions of the Newcomen Society, 67, 27-51.

Theil, H. (1967), Economics and Information Theory. North-Holland: Amsterdam.

Theil, H. (1972), Statistical Decomposition Analysis. North-Holland: Amsterdam.

Thurston, R. H. (1939), A History of the Growth of the Steam Engine [1878]. Cornell University Press: Ithaca, NY.

Torrens, H. (1994), 'Jonathan Hornblower and the steam engine: a historiographic analysis' in D. Smith (ed.). Perceptions of Great Engineers: Fact and Fantasy. Science Museum: London, pp. 23-34.

Usher, A. P. (1954), A History of Mechanical Inventions. Cambridge University Press: Cambridge.

Vincenti, W. G (1990), What Engineers Know and How They Know It. Analytical Studies from Aeronautical History. Johns Hopkins University Press: Baltimore, MD.

Vincenti, W. G. (1994), 'The retractable airplane landing gear and the Northrop "anomaly": variation-selection and the shaping of technology,' Technology and Culture, 35, 1-33.

von Tunzelmann, G. N. (1978), Steam Power and British Industrialisation to 1860. Clarendon Press: Oxford. 